\title{
Adoption of Biometric System to Manage Teachers Absenteeism for Improvement of Teachers Performance: A Case Study for Karuri High School in Kiambu County, Kenya
}

\author{
Alice Namiti *, Dr. Collins Oduor Ondiek ** \\ * Phd Student Educational Administration and Planning, University of Nairobi, Kenya \\ ** Assistant Professor Information Systems, United States International University, Nairobi, Kenya \\ DOI: 10.29322/IJSRP.10.05.2020.p10150 \\ http://dx.doi.org/10.29322/IJSRP.10.05.2020.p10150
}

\begin{abstract}
This study sought to establish the adoption of Biometric System to Manage Teachers Absenteeism for Improvement of Teachers Performance: A Case Study for Karuri High School in Kiambu County. The specific objectives of the study were: To determine the current methods used in schools in monitoring teacher's absenteeism, investigate the challenges faced in the use of the traditional methods. To determine the benefits of using biometric system to manage teacher's absenteeism in schools, determine factors affecting schools from using biometric systems and develop and validate an adoption framework for biometric system. The study adopted a descriptive research design and purposive sampling was used to collect data from the principal, deputy principals and the heads of departments and simple random sampling for teachers. Data was presented using tables, graphs and pie charts and analysed using frequencies. The findings from this study revealed that traditional ways the schools used in managing teachers absenteeism included attendance register, impromptu visits by the principal and the class prefects' records in checking the teachers' attendance. The challenges faced in the use of the traditional methods include teachers signing for others, ineffective policies and the loss of books. Also there is lack of motivation from students. The study revealed that traditional methods had many challenges in checking of teachers' attendance and therefore this negatively influences the teacher's performance. The study revealed that biometric system had a lot of benefits that schools can realize if the adopt it in managing teachers' absenteeism and for improvement of teachers' performance. The benefits of using biometric system was security of attendance tracking, its flexibility and convenience and the benefit of time saving. Also the study revealed that biometric had the benefit of being easily integrated with other systems.
\end{abstract}

Index Terms- Biometric System, Teachers absenteeism, Teachers performance, challenges, adoption framework

\section{INTRODUCTION}

$\mathrm{B}$ iometric time attendance system is for identifying every person coming to your place so that it can verify if the identified person is actually the one who he claims to be with its

This publication is licensed under Creative Commons Attribution CC BY.

http://dx.doi.org/10.29322/IJSRP.10.05.2020.p10150 time and other details (Garza \& Ricter, 2011). Biometrics technologies measures and analyzes individual characteristics such as fingerprints, irises, hand measurements and voice patterns. Biometrics are highly preferred because they cannot be hacked, forgotten, shared or stolen (Thakral et al., 2012). Thus uniquely identifying a person. Therefore, biometric technologies are supplementing or replacing traditional security methods because it does not require codes or passwords. Therefore, many organizations are preferring biometrics to solve security problems such as theft and fraud as well as recording attendance (Cappelli et al., 2007).

\subsection{Background to the research}

Computerized biometric attendance systems with advanced features have been used worldwide over time for management of employee attendance in organizations (Akinduyite, Adetunmbi, Olabode, \& Ibidunmoye, 2013). India is one of the countries with ambitious projects of biometrics such as the Unique Identifier (UID) project whose main goal is to create a unique biometric identity for every citizen of the country (Ramakumar, 2010). India has also done other project proposals such as biometric monitoring of judges in Delhi courts (K.Sarda, 2009) and biometric attendance tracking for both students and teachers in all the schools in the Indian state (http://secuwatch.wordpress.com). The small organisations are often not able to access biometric technology because even though the devices for biometric authentication are readily available, they are customized for a single purpose such as education and cannot be designed to suit the needs of other new domain such as healthcare (Kirmani, 2017) as well as due to lack of infrastructural resources. In spite of that, biometric upgrade is very important because it will reduce the rate of absenteeism and improve administrative efficiency as well as addressing the issue of teachers leaving school early and/ or not attending classes for personal work and thus abandoning their teachers' duty.

The India project is somehow related to another one that is initiated in Saudi Arabia whereby the ministry of education wants to implement the biometric attendance tracking system in all schools across the Country (Zhouheir \& Shuaib, 2011) as well as National biometric registry of all Saudi Arabia Citizens, this makes Aadhaar initiative to be the greatest and most ambitious 
national biometric program worldwide (Khan, 2010). It is noted that countries are getting used to monitoring government officials with biometric technology which seems a natural step to making the biometric attendance tracking find its way into the system of schools.

Hangzhou, a Chinese university has used a roll-call application powered by Artificial Intelligence (AI) to seize absentees and get the teachers back to classrooms. The system named class begins features AI technology developed by Hangzhou Dianzi University enables teachers to make class roll calls on the application, which takes less than 15 seconds, the system will automatically make phone calls to absent students.

A research conducted in Ghana, showed that biometric attendance system holds very good prospect for the management of attendance of teachers employed by the government and they were happy to announce that teacher absenteeism in Ghana had declined from 27 percent to 11\% (www.thebftonline.com, 2014). They also realised that the availability of the system is very dependent on the strength and speed of the GSM network technology adopted. That infers that its use can be limited in this regard (Charles, 2009).

In Kenya, the biometric attendance system is rarely used in secondary schools though some of the institutions like Jamhuri high schools, State house girls have deployed these methods. Therefore, this research aims at providing empirical data about knowledge of teachers on Biometric attendance system and its implementation on schools.

\subsubsection{Case study of Karuri high school}

Karuri high school is located at Kiambu County, Kiambaa Division, Karuri Location. It currently has a student population of about 1100 students all day scholars and approximately 50 teaching staff members. Teachers' absenteeism has been monitored for several years due to losses incurred by students due to lateness of the teachers in lessons attendances. Currently all the teachers sign an 'arrival observation book', but the method is not as effective in that teachers' cheat to avoid confrontation for late attendances (Saraswat et al. 2010). Given the proportion of teachers to the students, management of time by teachers is very crucial in Karuri high school. The use of books to sign in and out of every activity is regarded as time wastage.

\subsection{Statement of the problem}

Absenteeism is becoming of increasing concern in developing countries because some teachers receive payment without going for classes, which results, to waste of government resources. In addition, most educational systems and schools then incur heavy costs by having to employ substitute teachers where by Karuri high school is not an exception. Again, while the financial costs are important, the education costs are the most significant. This is because when teachers get miss school frequently it leaves students unattended, moreover teachers' absenteeism reduce the amount of teaching time and thus resulting to syllabus being incomplete or not well covered. Consequently, this results to low results by students (Ubongo, 2004). Bray and Percy (2003) noted that teacher's absenteeism has a large and swayful results on the nation's education system therefore high level of teacher's absenteeism affect student's achievement negatively.

\subsection{Research Objectives}

The objectives of the research were:

i. To determine the current methods used in schools in monitoring teacher's absenteeism.

ii. To investigate the challenges faced in the use of the traditional methods.

iii. To determine the benefits of using biometric system to manage teacher's absenteeism in schools.

iv. To determine factors affecting schools from using biometric systems.

v. To develop and validate an adoption framework for biometric system.

\subsection{Scope of the research}

This study research was based on the use and application of BAS and the implementation process to ensure best practice management in Karuri High School. Primary data was collected using questionnaires hence the accuracy of the same depended on the honesty of the respondents. The administration of the high school was also involved hence raising the question if they was willing to assist in the research due to sensitivity of their offices. However, the board members and students were not involved. Bearing also in mind that the best practice management of attendance should be practiced in all high schools, the research was limited to only Karuri High School.

\subsection{Significance of the study}

The information generated from this study may be lead to improve future programing, accelerate progress towards EFA and MDGS. When EFA and MDGS are met, there is improved quality of education with expanded early childhood and care. The study is very important to the secondary school's administrators' and policy makers because it establishes the major causes of teachers' absenteeism therefore changing the behavior of teachers towards their job performance. In addition, it will also provide additional dimensions for evidence-based intervention; stimulate further research and documentation of good practice for containment of teachers' absenteeism. Therefore, Biometric attendance system tends to inhibit the realization of Education for All (EFA) and achievement of United Nations' Sustainable Development Goals (SDGs) 4 that is provision of quality education which will ensure that by 2030 all pupils and students acquire equitable free and quality primary and secondary education by syllabus coverage leading to effective learning outcomes. Which is also important in determining how efficient and effective the services offered by the institutions tend to be as well as the interest of students who benefit from these institutional services.

\section{LITERATURE REVIEW}

This section looks at the literature review of adoption of biometrics in managing teachers' absenteeism.

\subsection{Introduction to Literature Review}

In any organization, be it private or public, small or big, attendance of employees is very crucial aspect. It is mainly used to monitor how punctual the employees of any given organization tend to be and thus informed the management about the discipline 
of that organization this is because both are directly proportional to each other therefore resulting in better management of the activities in that organization (Kirmani, 2017). Different schools have different approaches to record attendance of students and staffs across the world (Shoewu, Olaniyi \& Lawson, 2011); Manual system is one of these approaches used to acquire the attendance of employees and srudents in education sectors. However, the manual system is being replaced by biometric attendance system. Moreover, more emphasis on use of biometric system have been put on education and health sector as they are the majorly discussed departments where biometric attendance system need installation and implementation. This research focuses on a couple of factors ranging from earlier methods used to record attendance of teachers as well as how biometric attendance system can be a solution to absenteeism of teachers in schools. From the reviewed literature review, it is evident that peer-based learning has experienced a paradigm shift and has embraced ICT and its surrounding technologies.

\subsection{Theories that support the research}

This research was supported by the theories: Innovationdiffusion theory and Technology Acceptance theory by Fred Davis.

\subsubsection{Innovation-diffusion theory}

In 1995 Roger proposed the theory of innovation-diffusion which was to enhance the foundation of conducting research on adoption and innovation acceptance. His research was synthesized from over 508 diffusion studies which resulted to the 'diffusion of innovation' theory where by the individuals, groups and organization were to adopt various innovations. The theory explains in details the procedures for which an innovation is passed through specific routes over time among the members of a social systems (Rogers, 1995).

\subsubsection{Technology Acceptance Model}

This is among the most swayful model of technology acceptance. In 1989 Davis suggested the Technology Acceptance Model (TAM) with two main factors that affect the usage of new technology by an individual in regards to his or her intentions. That is how easy it is to use and how important its usage is to an individual or group. Example when an old person finds digital games to be very difficult to play or as a waste of time they will be unlikely to accept this technology but for an older person who finds digital games to be easy to learn or as a way of providing needed mental stimulation they will be more likely to accept to learn how to use the digital games thus adopting the technology. Though TAM has been criticized in different ways, it functions as an important general framework and it is very consistent with different research being done on the factors that affect older adults' intention to use new technology (Braun, 2013).

\subsection{Traditional challenges of repositories in peer-based learning}

Traditionally, repositories are in form of note taking, printouts, handouts, memorizations and recitations. These come with many challenges. Note taking and writing down learnt material consumes a lot of time in comparison to typing, audio recordings and video conferencing. This makes traditional repositories cumbersome in nature.

The availability of a printouts and handouts for information does not necessarily imply that all the content therein is required by a user. This bulkiness of printout can deter peers from using traditional repositories when compared to digital repositories where one sifts and accesses the information that they require at any given time and wherever they are limiting the constraints of time and space.

More often traditional repositories limit the access of information with many incidences of either loss or lack of the needed content.

When it comes to currency of content in traditional repositories, one of the challenges experienced is the lag in time to renew and upgrade content. This is because it takes time to deposit, verify, edit, print and physically distribute content.

Memorization and recitation of content comes with the challenge of peer idiosyncrasies which can present the risk of misinformation, disinformation and unavailability of data.

\subsection{Current methods used in schools to reduce absenteeism of teachers \\ Use of record books}

A record book also known as arrival book was the main method of keeping records for acquiring attendance of both teachers and students at different levels of the education department in schools. The entries in record books were normally made based on designation and/or seniority in the school. Each entry of this book had a teacher's phone number, name, position or designation and signature. In this traditional method, the use of books/registers were used in maintaining the attendance whereby 000this information about the attendance was forwarded to the head office for weekly or monthly check routine.

\section{Incentives}

Education agency administrators motivate teachers by providing incentives thus curb absenteeism since the teachers are able to meet their needs and feel that they are valued in schools (Jacobs \& Kritsonis, 2007). It is always advised that the education agency administrators should make investments on incentives for teachers earlier on to prevent them from being hesitant on providing incentives due to budgetary restrictions thus making it long-term and saving large amount of costs (Jacobs \& Kritsonis, 2007). For example, the Aldine Independent School District in Texas managed to save approximately 284,000 US dollars as well as making the number of teachers with excellent attendance to double in one year by rewarding similar contributions that is incentives to teachers (District Management Council, 2004).

\section{Motivation to teachers}

Teachers should be given motivation to work well without hesitation for example, it may be so respectful for the management at schools to allow leaves to teachers therefore creating opportunities for teachers to participate in professional workshops, meetings or conferences during periods that do not interfere with the teachers scheduled classes thus enhancing their skills as well as getting motivated to work hard (Pitkoff, 2003; Hanover Research, 2012). Teachers with the best attendance records would be appraised at celebrations held by the school whereby they win 
substantial prizes like a new car, laptops, lump sum amount of money among others.

\section{School policies}

Reevaluation of school procedures and policies related to teacher attendance have always improved teachers' attendance in schools thus reducing absenteeism. Studies suggests that changes in school policies and procedures can result in noticeable impacts on the rate of teacher absenteeism, starting with small changes to given practices then larger changes are visible that is systemic adjustments. Examples of a larger change to policy which has had an impact on managing absenteeism is seen in the report that examined the four-day school weeks implementation across rural school districts in South Dakota, Colorado, Louisiana, Wyoming, Nebraska, New Mexico and Idaho whereby In every case the attendance rates for teachers and students was noted to have risen following the change to the four-day school weeks, the change was ranging from $2.0 \%$ to $50.0 \%$ in teacher attendance and from $2.0 \%$ to $5.8 \%$ increases in student attendance (Beesley \& Anderson, 2007).

\section{Favorable work environment}

Providing work environment that is conducive for teachers has also been used to reduce absenteeism of teachers in schools. When teachers' well-being is investigated the work implementation of place environment for those teachers is improved and thus having substantial pay-off in reducing the time spent out of the classroom (Fickes, 2011). Research studies also imply that when the relationship among teachers and school staffs is so good and positive, moreover school leadership, it plays an important role in determining the perceptions of workplace environments and in return, influences teachers' decisions to go to school every day (Owen, 2010; Harrison, Labby, \& Sullivan, 2015).

\subsection{Challenges for using those methods}

Loss of books - The use of record books to register attendance of students and teacher's method could easily lead to loss of the record book. This is because when the teachers or students know that the weekly/monthly routine is close and penalties will be reinforced to the undisciplined ones the book would be stolen so that it can be missing and thus no penalties charged.

Teachers signing for other teachers - This manual system would provide an employee with an opportunity to sign the arrival book anytime during the day even when he or she has arrived late and in some instances the personal approach of an employee with the person in charge can mark the attendance on his or her behalf easily through signing in advance or even on the days when the person was actually absent from school (Kadry and Smaili, 2010).

Ineffective policies - Some policies put in place are not effective since teachers ignore them or the management do not do a follow up for the policies not followed thus teachers take advantage since no repercussions. It is very difficult for the government to provide miscellaneous incentives to teachers since they find it very costly.

Lack of motivation from students - This is another challenge that leads to absenteeism of teachers. This is because when the students are absent from class or are not willing to learn the teachers will become less motivated and thus contribute to increased absenteeism. Having all these challenges in mind the need to implement Biometric Attendance System is very crucial, which will result in managing absenteeism within the school.

\subsection{Benefits of using biometric system to manage absenteeism}

Time saving - It is very fast; once the user gets to the system all the details required such as time will be automatically recorded. Through this a lot of time is saved and still the records details are very accurate (Shehu \& Dika, 2011) thus one can avoid recording details early, late or the friends recording details for them very easily. Therefore, biometric time attendance system helps one to focus on the core business by avoiding time tracking issues in the quickest and easiest way.

Security of attendance tracking - Biometric Time Attendance is very secure as compared to manual tracking. Therefore, students will not lie that they attended lessons yet they were at home since only teachers have access to the information in the system and so it cannot be altered. Biometric time attendance system has been used in many shopping malls for security purpose and it has really worked a lot. Biometric features are so unique and therefore offer limited deniability due to its enhanced security.

Flexibility - Biometric attendance system can be easily integrated with other systems for example if someone wants to use the system for business or organization then they can easily integrate it to account systems, billing systems and payroll systems. Therefore, it is very flexible because it shows that the time attendance system can be used for all type of businesses and organizations with great flexibility. It is also very user friendly thus ease of use.

Convenient - use of biometrics is more convenient because it is very fast with physical user interaction with the system and very streamlined mimicking how people recognize and trust people they know. Moreover, users are not able to forget their biometrics since it does not require codes or passwords.

Reduced cost - Despite of installation and implementation of biometric recognition and authentication into a system having some certain investment cost, when the system is deployed correctly it offers opportunities that decreases the operational costs through simple processes such as self-service automation which gives a decreased need for manual work and hence reduced cost of employing substitute teachers and also payment of teachers who have not worked due to high rate of absenteeism this will ultimately reduce absenteeism with greater margins.

Accuracy - Biometric technology can also help in tracing and monitoring accurately the employee time of arrival and departure as well as attendance which can help in prevention of time loss by making sure that employees arrive at their work place on time and leave at the right time after work (Ononiwu \& Okorafor, 2012) this will reduce the rate of absenteeism of teachers as well as motivating students to work hard since the teachers are available for consultation.

Can easily be integrated to other systems - Existing information systems can be integrated with biometric system to make operations better thus facilitating a faster, accurate and precise as well as secure access of people to important information, areas among other transactions. Integration to other 
systems can be done at different levels that is from the platform to component level where at the platform level biometric systems can be integrated with the organization's other softwares and hardwares (Wangler \& Paheerathan, 2000).

\subsection{Challenges of biometric system}

Education level - Abdelbury (2011) argues that the confidence of the high quality of information generated from biometrics, how easy it is to use, the value-added by biometrics and the technological intent were all related to the education level. Thus if the education level is low the person will be resistant to adopting the technology unlike those who are more informed due to high education level.

Location - There difference in the ease of implementation of biometrics in relation to location of placement of the biometric technology was very significant. The location is also influenced by the availability of infrastructural resources where areas that are more developed implement the biometrics so easily as compared to the undeveloped areas.

Cost - In spite of the biometrics technology having so many pros, the cost of acquiring and maintaining a biometric machine is of major concern to its use as a means of monitoring in school management. However, the school management may be able to acquire one but the issue of maintenance when it becomes faulty has pose of a major setback to school monitoring absenteeism in schools. Therefore, biometrics is an expensive system.

Age - Abdelbury (2011) conducted a research to different age groups whereby from his results he noted that there is difference in biometrics knowledge with participants aged between 29 and 39 years being more informed than the participants between the age of 18 and 28 years. While older participants above 51 years faced challenges with the use of biometrics when compared to the participants between 18-28 years of age.

Data integrity - The use of biometric systems can lead to degradation of Information legitimate data transformation or manipulation or even data being corrupted leading to security gaps, inappropriate use, or mismanagement. The biometrics can also be inappropriately used to a context other than the one for which it was created for originally leading to mission creep this includes using of data collected in a domain that demands high data integrity for a domain that is purely for the sake of convenience or inappropriate re-use of information.

Variation within persons - Change in environment, diseases, age, stress, training, occupation factors may affect the biometric characteristics and the information recorded by the biometric systems. Moreover, intentional alterations, prompting, sociocultural aspects of the condition in which the presentation occurs as well as changes in human interface with the system can affect the biometric characteristics and information in the system. Therefore, each interaction of the user with the system is associated with different biometric information from the initial one thus affecting the whole system. Individuals attempting to prevent recognition for their own reason also contribute to the inherent uncertainties in the biometric systems. Also, the fingerprint of people who work in laboratory are often affected and thus the use of fingerprint as mode of authentication is not applicable to them.

\subsection{Factors affecting biometric system}

People depend on technology to give reproducible and reliable services in the education sector. The new innovated technology can either be accepted or rejected depending on many factors which influence the adoption of the technology by people. A technology is only considered successful if employees embrace and use the technology effectively (Lee, Kim, Rhee, \& Trimi, 2006). The use of these technology is influenced by several factors like:

Availability of Technology - For a technology to be mature enough for use it requires more attention than it seems obvious. In 2009, Pooe found out that the biometric system technology was not mature enough for it to be used in the education sector.

Inadequate Policy - A study by Heeks (2006) showed that ICT policies in developing countries proved that there is a lack of enthusiasm by decision makers to begin ICT projects especially on Curriculum of Kenya Education. This study was in line with the study that showed that policy framework influenced ICT implementation.

Lack of infrastructural resources - Infrastructural facilities play a significant role in biometric implementation (Nachmis et al., 2004). Therefore, it is very difficult to adopt biometric attendance systems in institutions that have limited infrastructural facilities that should be available for the support of the system.

Lack of administrative support - Teachers that get adequate ICT support from their management are more likely to use ICT during teaching practices more than those that do not receive ICT support from their management or administrators thus they are not likely to integrate with technology like biometric systems (Kariuki, 2004). Lack of managerial support leads to lack of finances for installation and implementation.

Training - This plays a critical role on ICT implementation. This is because people are informed and are aware of the value added by technology advancement and this leads to more acceptance of biometric system in schools. Tedre (2004) stated that there is need of teachers learning ICT first before integrating them in the curriculum of education thus making ICT simple to implement and adopt.

Anti - spoofing capabilities - As biometric attendance systems become popular and widely used, malicious users may gain accessibility to the system thus causing possible direct attacks. These attempts are referred as spoofing attacks. Therefore, secure anti-spoofing protection is a necessity for the school so as to have the capability for the right biometric modality.

Acceptability - For a successful biometric management installation, user acceptance is required. Some of the biometric technologies may have a stigma related with them such as fingerprints and criminality which can have a negative impact on user perception in certain cultures. Understanding which modalities are allowed versus those which may cause user acceptance issues is important.

Cost-effectiveness - In choosing the best and most effective biometric hardware modality, cost is a crucial factor to consider. Based on the available technology and hardware characteristics, some modalities can be more cost effective than others. It's therefore important to recognize that an initial 
investment in biometrics can and is quite often recouped in a short period of time to achieve a fast Return on Investment (ROI).

\subsection{Other authors related work and findings}

This section conceptually illustrates the critical review of the works and attempts by different authors in details and highlights their main-findings and technology used. These works main aim is to determine and eliminate the lack for the traditional methods and techniques regarding attendance management systems. Whereby the majority of articles have focused on developing such systems to support academic facilities in education (Arif, 2018).

\subsubsection{Conceptual Framework}

\subsection{Research Gap}

Biometric system technology is a very important technology used for tracking time attendance for employees (Smart Cart Alliance Identity Council, 2007). Oloyede et al. (2013) did a research on use of biometric technology to manage absenteeism of staffs but the research did not mention any software to address the problem of attendance. Therefore this study will help us know the challenges of the current method of monitoring absenteeism and how the use of biometric system can be of help to solve those challenges. 


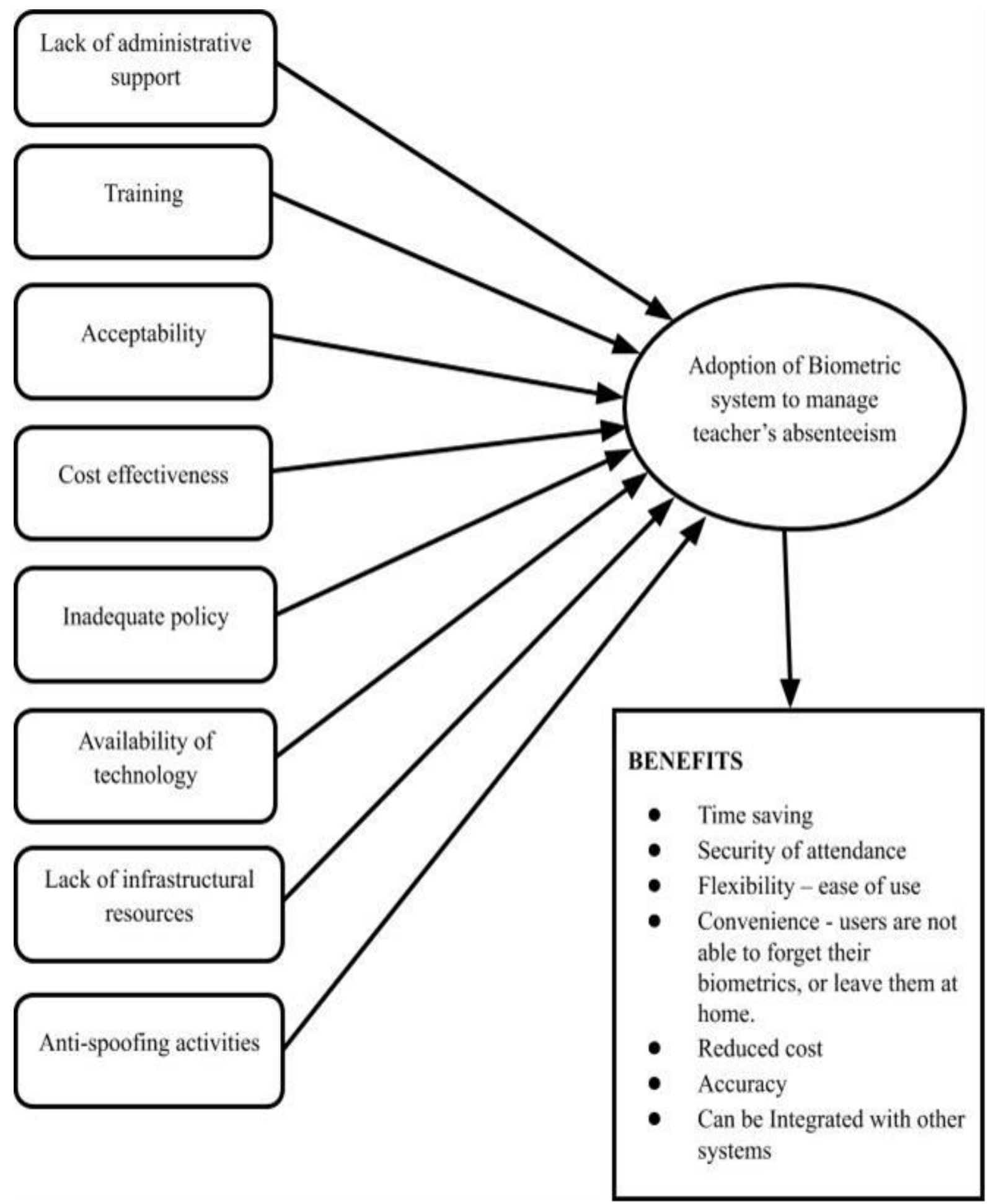

\section{Research DESIGN AND Methodology}

This section presents the research design, target population, the procedure followed in data collection and the techniques used in data analysis.

\subsection{Research Design}

The type of the research design to be used will be descriptive research. This is a type of research, which is structured and precisely intended to gauge the features stated in research questions. This research will focus on the raw data collected from the respondent who will be given the questionnaires to fill out the questions relating to the topic, during the actual social survey. All staff members at Karuri high school will be the respondents of the questionnaire hence suiting the need for the research.

\section{Target Population}

The study population was the 1 principals, 2 deputy principal, 60 teachers and the 10 heads of departments at Karuri 
high school. The study included the principal because he is the overseer of the teachers' attendance in the school. The heads of departments were included because they manage the operations in their various departments including checking the teachers attendance while the teachers were included because they are the once who use the biometric system.

\section{Sampling Technique}

This study involved the staff of the school that included the principal and the deputy principal, heads of department and the teachers in the study led to gathering of information that covered the findings on adoption of biometric system to manage teachers' absenteeism for improvement of teacher's performance. The principal and the deputy principal were purposively sampled while the teachers were sampled using simple random sampling. The heads of department selected had to meet the inclusion criteria required by the study through answering questions which were in questionnaire.

\section{Data collection procedure}

The procedure was conducted in the year 2019 where the researchers issued questionnaires to the respondents in Karuri High School. In this process, the interviewers personally conducted this survey and each staff was requested to fill out the questionnaire. The structured questions were for the researchers to get to know their views concerning the topic under discussion; only close-ended questions were used. As soon as the process is complete, the filled questionnaires were collected for data analysis.

\section{RESULTS AND DISCUSSION}

\subsubsection{Distribution by gender}

The study sought to establish the distribution by gender of the respondents in selection of the sample. It was observed that majority $(60 \%)$ of the respondents were male while $40 \%$ of the sample were female. This was interpreted to mean that more males than females make the population of teaching staff at Karuri High School.

\section{Figure 1. Distribution by gender}

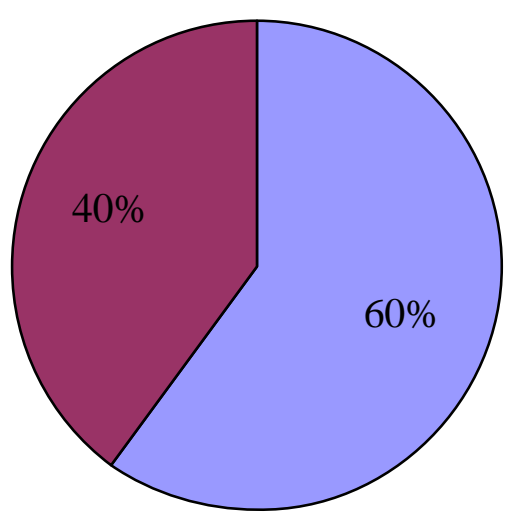

Source: Author data 2020

\subsubsection{Distribution by Age Bracket}

The respondents were asked to provide data on their age brackets. The age bracket was important so as to compare the different age groups whereby there might be difference in biometrics knowledge with participants' ages where the older might be more informed than the participants' younger participants. While very old participants might face challenges with the use of biometrics when compared to the participants who were younger. The research indicated that, 62 percent of the respondents were of ages between 31-40 years, 20 percent were of ages between 41-50 years, while 14 percent were between 20-30 years. The age brackets was found to influence the kind the teachers' ability to use the biometric system.

Abdelbury (2011) conducted a research to different age groups whereby from his results he noted that there is difference in biometrics knowledge with participants aged between 29 and 39 years being more informed than the participants between the age of 18 and 28 years. While older participants above 51 years faced challenges with the use of biometrics when compared to the participants between 18-28 years of age.

Table 2. Distribution by age bracket

\begin{tabular}{lll}
\hline Age bracket & Frequency & Percentage \\
\hline 20-30 years & 8 & 14 \\
31-40 years & 35 & 62 \\
41-50 years & 11 & 20 \\
$>51$ years & 3 & 4 \\
Total & $\mathbf{5 7}$ & $\mathbf{1 0 0}$ \\
\hline
\end{tabular}

Source: Author data 2020

\subsubsection{Distribution by duration in teaching profession}

The respondents were asked to provide data on the number of years in the teaching profession. The number of years was an indication of the experience the respondents had in understanding the adoption of biometric system to manage teachers absenteeism and for improvement of teachers performance. The research revealed that, 19 percent of the respondents had $1-2$ children, 22 percent had $3-4$ children, while the majority 48 percent had between $4-9$ children. The level of experience was found to influence the level of understanding of the respondents of the adoption of biometric system to manage teachers' absenteeism for improvement of teachers' performance, the level of understanding of those with a more number of experience in the teaching profession was higher and hence were more productive in terms of $\square$ Male
$\square$ Female 
Figure 2. Length of time in the teaching profession

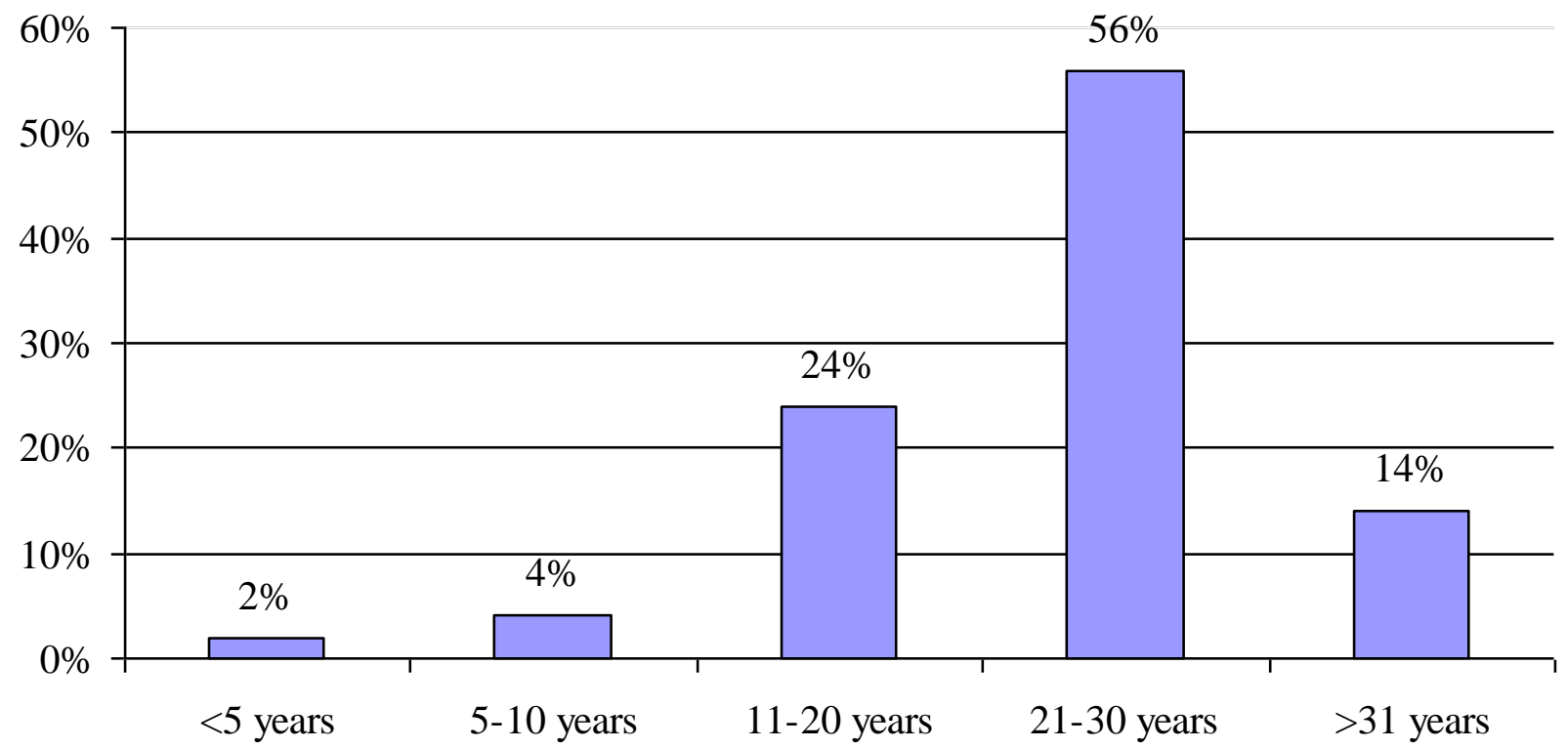

\section{Source: Author data 2020}

4.3 Results on the current methods used in schools in monitoring teacher's absenteeism

The respondents were asked to provide data on the current methods used in schools in monitoring teachers' absenteeism. The study asked this questions in order to find out the difference between the traditional methods used by schools and the biometric system. The research revealed that $(68 \%)$ of the respondents indicated that they used attendance register while 22 percent revealed that they used impromptu visits by the principal. Also the research revealed that 10 percent of the respondents used class prefects' records in checking the teachers' attendance. The research revealed that there are various other methods other than the biometric system used to check the teachers' absenteeism. Different schools have different approaches to record attendance of students and staffs across the world (Shoewu, Olaniyi \& Lawson, 2011); Manual system is one of these approaches used to acquire the attendance of employees and srudents in education sectors.

Table 3. Current methods used in schools in monitoring teachers' absenteeism

\begin{tabular}{lll}
\hline Current methods & Frequency & Percentage \\
\hline Attendance register & 39 & 68 \\
Impromptu principal visits to staffroom & 12 & 22 \\
Class prefect records & 6 & 10 \\
Total & $\mathbf{5 7}$ & $\mathbf{1 0 0}$ \\
\hline
\end{tabular}

Source: Author data 2020

\subsection{Results on the challenges faced in the use of the traditional methods}

The respondents were asked to provide data on the challenges they faced in the use of the traditional methods. 72 percent of the respondents indicated that one of the challenges of using the traditional methods was teachers signing for others, 12 percent of the respondents revealed the challenge to be ineffective policies while 8 percent indicated the challenge of traditional method to be loss of books. Also the study revealed that 8 percent of the respondents had a challenge of lack of motivation from students. The study revealed that traditional methods had many challenges in checking of teachers' attendance and therefore this negatively influences the teacher's performance.

Abdelbury (2011) argues that the confidence of the high quality of information generated from biometrics, how easy it is to use, the value-added by biometrics and the technological intent were all related to the education level. Thus if the education level is low the person will be resistant to adopting the technology.

\section{Table 4. Challenges faced in the use of the traditional} methods 


\begin{tabular}{lll}
\hline Challenges faced & Frequency & Percentage \\
\hline $\begin{array}{l}\text { Teachers signing for } \\
\text { others }\end{array}$ & 42 & 72 \\
$\begin{array}{l}\text { Loss of books } \\
\text { Ineffective policies }\end{array}$ & 4 & 8 \\
$\begin{array}{l}\text { Lack of motivation } \\
\text { from students }\end{array}$ & 4 & 12 \\
$\quad$ Total & $\mathbf{5 7}$ & 8 \\
\hline
\end{tabular}

Source: Author data 2020

4.5 Results on the benefits of using biometric system to manage teacher's absenteeism in schools

The respondents were asked to provide data on the benefits of using biometric system to manage teacher's absenteeism in school. A majority $(80 \%)$ of the respondents indicated that one of the benefits of using biometric system was security of attendance tracking, 13 percent of the respondents revealed its flexibility and convenience and 5 percent indicated the benefit of time saving. Also the study revealed that 2 percent indicated that biometric had the benefit of being easily integrated with other systems. The study revealed that biometric system had a lot of benefits that schools can realize if the adopt it in managing teachers' absenteeism and for improvement of teachers' performance.

A research conducted in Ghana, showed that biometric attendance system holds very good prospect for the management of attendance of teachers employed by the government and they were happy to announce that teacher absenteeism in Ghana had declined from 27 percent to $11 \%$ (www.thebftonline.com, 2014). They also realised that the availability of the system is very dependent on the strength and speed of the GSM network technology adopted. That infers that its use can be limited in this regard (Charles, 2009).

Table 5. Benefits of using biometric system

\begin{tabular}{lll}
\hline $\begin{array}{l}\text { Benefits of using } \\
\text { biometric system }\end{array}$ & Frequency & Percentages \\
\hline
\end{tabular}

\begin{tabular}{|c|c|c|}
\hline Time saving & 3 & 5 \\
\hline $\begin{array}{l}\text { Security of attendance } \\
\text { tracking }\end{array}$ & 45 & 80 \\
\hline $\begin{array}{l}\text { Flexibility and } \\
\text { convenience }\end{array}$ & 7 & 13 \\
\hline $\begin{array}{l}\text { Can be easily } \\
\text { integrated with other } \\
\text { systems }\end{array}$ & 2 & 2 \\
\hline Total & 57 & 100 \\
\hline
\end{tabular}

Source: Author data 2020

\subsection{Results on the factors affecting schools from using biometric systems}

The respondents were asked to provide data on the factors affecting schools from using biometric systems. A large number 52 percent of the respondents indicated that lack of infrastructural resources was a factor that affected their school from using biometric systems. Another 30 percent of the respondents revealed that lack of administrative support hinders them from adopting the biometric systems. Also the study revealed that 10 percent of the respondents indicated that inadequate policies affected their use of biometric systems. A few (8\%) indicated that training was a factor affecting their school from using biometric systems. The study revealed that there were various factors that influence the schools adoption of a biometric system in managing teachers' absenteeism.

This finding is supported by Tedre (2004) who revealed that training plays a critical role on ICT implementation. This is because people are informed and are aware of the value added by technology advancement and this leads to more acceptance of biometric system in schools. He stated that there is need of teachers learning ICT first before integrating them in the curriculum of education thus making ICT simple to implement and adopt.

Table 6. Factors affecting schools from using biometric systems

\begin{tabular}{lll}
\hline Factors affecting schools from using biometric systems & Frequency & Percentages \\
\hline Inadequate policy & 6 & 10 \\
Lack of infrastructural resources & 29 & 52 \\
Lack of administrative support & 17 & 30 \\
Training & 5 & 8 \\
Total & $\mathbf{5 7}$ & $\mathbf{1 0 0}$ \\
\hline
\end{tabular}

Source: Author data 2020

\subsection{Development and validation of an adoption framework for biometric system}

Respondents were asked if they would recommend the school to adopt use of biometrics system to manage absenteeism among teachers and responded as indicated in Figure 4.3. The respondents highly recommended the adoption of biometric system in managing teachers absenteeism with 28 (90\%) affirming the need and only 4 (10\%) negating the need of adopting biometric system quoting 'lack of internet connectivity and lack of requisite ICT training in teachers to effectively adopt biometric system.' 
Figure 3. Recommend the school to adopt use of biometrics system to manage absenteeism among teachers
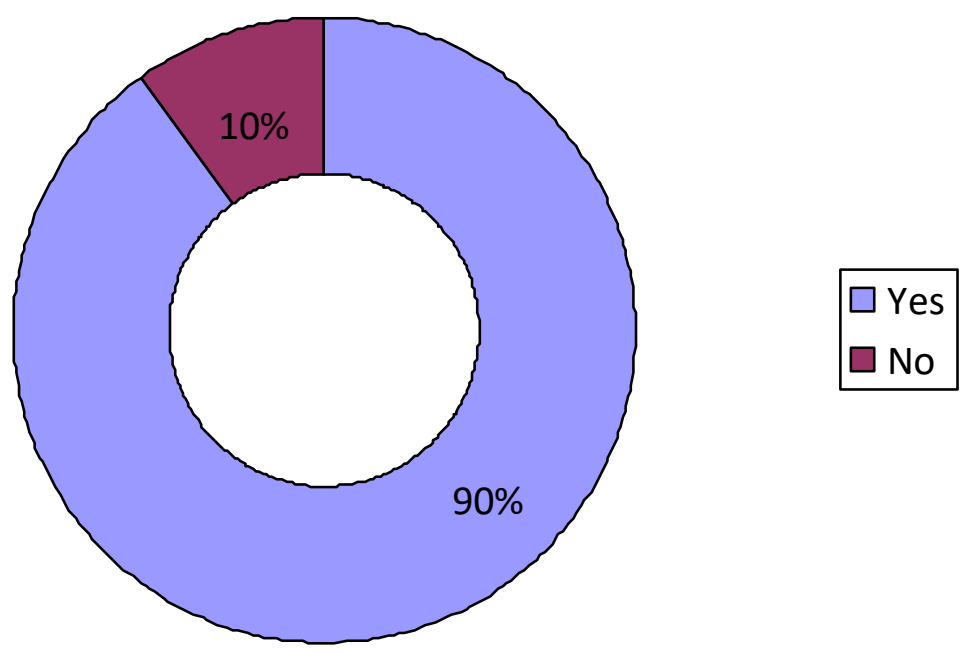

Source: Author data 2020

The study sought to develop and validate an adoption framework for biometric system. To achieve the objective four of this study the following function was used.

$\mathrm{Y}=\mathrm{F}_{1 \ldots 6}\left(\mathrm{X}_{1 \ldots 6}\right)$

Where:

$\mathrm{Y}$ is the dependent variable

$\mathrm{F}=$ Independent variable

$\mathrm{X}=$ Intervening variables

$\mathrm{F}_{1}=$ Administrative support, $\mathrm{F}_{2}=$ Training, $\mathrm{F}_{3}=$ Accessibility, $\mathrm{F}_{4}=$ Cost effectiveness, $\mathrm{F}_{5}=$ Inadequate policy, $\mathrm{F}_{6}=$ Availability of technology

$\mathrm{X}_{1}=$ Lack of ICT infrastructure, $\mathrm{X}_{2}=$ Lack of administrative support, $\mathrm{X}_{3}=$ ICT sensitization, $\mathrm{X}_{4}=$ Cost of ICT, $\mathrm{X}_{5}=$ Time and effort, $\mathrm{X}_{6=}$ ICT policy.

\section{CONCLUSION}

This study highlights the impact of adopting biometric system in managing teachers' absenteeism in improving the teachers' performance. This traditional ways the schools used in managing teachers absenteeism included attendance register, impromptu visits by the principal and the class prefects' records in checking the teachers' attendance. The challenges faced in the use of the traditional methods include teachers signing for others, ineffective policies and the loss of books. Also there is lack of motivation from students. The study revealed that traditional methods had many challenges in checking of teachers' attendance and therefore this negatively influences the teacher's performance. The study revealed that biometric system had a lot of benefits that schools can realize if the adopt it in managing teachers' absenteeism and for improvement of teachers' performance. The benefits of using biometric system was security of attendance tracking, its flexibility and convenience and the benefit of time saving. Also the study revealed that biometric had the benefit of being easily integrated with other systems.

Lack of infrastructural resources was a factor that affected the school from using biometric systems. Lack of administrative support hinders them from adopting the biometric systems. Also the study revealed that inadequate policies affected their use of biometric systems. Training was also a factor affecting their school from using biometric systems. The study revealed that there were various factors that influence the schools adoption of a biometric system in managing teachers' absenteeism.

\section{RECOMMENDATION}

i. The school management should create an suitable policies that will encourage the integration of biometric system in managing the teachers absenteeism.

ii. Provide adequate resources to purchase the biometric system in school.

iii. The government should through the ministry of Education should train the teachers on the use of biometrics and their importance in improving the performance in schools.

\section{REFERENCES}

[1] Bolle, R. (2004). A guide to biometrics. New York: Springer.

[2] Chirillo, J. (2003). Implementing Biometric Security.

[3] Garza, G., \& Ricter, L. (2011). What is a biometric reader? Bright Hub Inc.

[4] Kadry, S., \& Smaili, M. (2010). "Wireless Attendance Management System Based on Iris Recognition". 
[5] Lee, H. M. (2003). Traceability of double spending in secure electronic cash system. Proceedings of International conference on computer networks and mobile computing, IEEE computer society

[6] Pato, J., \& Millet, L. (2010). Biometric recognition: Challenges and opportunities. Washington DC: The Naional Acdemies Press. Retrieved March 9, 2010

[7] Robert, C., Ron, M., \& Dan, M. (2005). “Automated fingerprint identification systems", Technical Report by Computer world donors case study.

[8] Saraswat, C. (2010). "An Efficient Automatic Attendance System using Fingerprint Verification Technique”. International Journal on Computer Science and Engineering. 2(02):264-269.

[9] Shoewu, O.O., Olaniyi, M., \& Lawson, A. (2011). "Embedded ComputerBased Lecture Attendance Management System”. African Journal of Computing and ICT (Journal of IEEE Nigeria Computer Section). 4(3):27 36.

[10] Syed, M.S. (2015). Effectiveness of Gaussian and Average Noise Reduction Filters on Ideal Fingerprint Image in Biometric Fingerprint Identification
System. International Journal of Recent Scientific Research. 6(8), 57315736.

[11] Thakral, P., Rai, M., \& Thakral, R. (2012). Issues of biometric for disabled. International Journal of applied Engineering research, Vol. 7. No.11.

[12] Thamer, A., \& Drew, S. (2010). Employees Perceptions of Biometric Technology adoption in E-Government. An exploratory study in the Kingdom of Saudi Arabia.

\section{AUTHORS}

First Author - Alice Namiti, Phd Student Educational Administration and Planning, University of Nairobi, Kenya namitialice@gmail.com

Second Author - Dr. Collins Oduor Ondiek, Assistant Professor Information Systems, United States International University, Nairobi, Kenya, coduor@usiu.ac.ke 